J. Lake Sci. (湖泊科学), 2012, 24(5): 797-800

http: //www. jlakes.org. E-mail : jlakes@niglas.ac.cn

(C) 2012 by Journal of Lake Sciences

\title{
中国鱼腥藻属的两个新记录种”
}

\author{
李守淳 ${ }^{1}$, 柴文波 ${ }^{1,2}$, 郑洪萍 ${ }^{3}$, 耿军灵 ${ }^{3}$, 李仁辉 ${ }^{2 * *}$ \\ (1: 江西师范大学生命科学学院, 南昌 330022) \\ (2: 中国科学院水生生物研究所,武汉 430027) \\ (3: 福建省环境监测中心,福州 350003)
}

摘 要: 迄今为止,全球范围共报道出 100 多种鱼腥藻, 中国记录报道的仅有 50 余种,但有些种类的描述仍较模糊. 最近 在福建、浙江等地进行野外调查时, 发现了多种丝状蓝藻. 其中就有 2 种鱼腥藻在中国尚未报道: 威格鱼腥藻 (Anabaena viguieri Denis et Frémy 1923) 和史密斯鱼腥藻 (Anabaena smithii (Komárek) Watanabe 1992).

关键词: 鱼腥藻属;中国;蓝藻;新记录;水华

\section{Two newly recorded species of Anabaena(Nostocales, Cyanobacteria) in China}

\author{
LI Shouchun ${ }^{1}$, CHAI Wenbo ${ }^{1,2}$, ZHENG Hongping ${ }^{3}$, GENG Junling ${ }^{3}$ \& LI Renhui ${ }^{2}$ \\ ( 1 : School of Life Sciences in Jiangxi Normal University, Nanchang 330022, P. R. China) \\ (2: Institute of Hydrobiology, Chinese Academy of Sciences, Wuhan 430027, P. R. China) \\ (3: Fujian Provincial Environmental Monitoring Center, Fuzhou 350003, P. R. China)
}

\begin{abstract}
So far, more than 100 species of genus Anabaena have been recorded in the world, and about 50 taxa were described in China. During our recent field investigations for water-bloom forming cyanobacteria in China, several filamentous cyanobacterial species were examined in the samples. In this study, we demonstrated that two Anabaena species as Anabaena viguieri Denis et Frémy 1923 and Anabaena smithii (Komárek) Watanabe 1992, had never been reported in China, and they are newly described and discussed in the present study.
\end{abstract}

Keywords: Anabaena; China; Cyanobacteria; new record; water bloom

近年来,水体富营养化所引起的蓝藻水华的暴发已经成为世界上许多区域的典型生态问题. 蓝藻水华 的暴发不仅对水体造成严重的污染,而且会释放出毒素和异味物质对水体本身及其周围居民的健康等都造 成诸多不利影响 ${ }^{[1]}$. 在我国发生的蓝藻水华的种类中, 由于微囊藻 (Microcystis) 水华发生的频度高、范围广、 规模大以及毒性强, 故对其各方面的研究及报道较多 ${ }^{[2]}$; 而对其它水华的蓝藻种类如鱼腥藻 (Anabaena), 束 丝藻 (Aphanizomenon) 和浮丝藻 (Planktothrix) 的研究和报道偏少 ${ }^{[34]}$. 鱼腥藻的形态、生理、生态以及产生的 代谢产物如毒素的多样性均很高,但是对其进行的基础研究,如分类学研究不够完善,报道的种类很少,制 约了开展更深人的研究. 迄今为止, 全世界范围内报道了 100 多种鱼腥藻, 其中 Geitler 记录了 87 个分类单 位 ${ }^{[5]}$, Kondrateva 记录了 78 个分类单位 (Taxa) ${ }^{[6]}$,Starmach 则报道了 92 个分类单位 ${ }^{[7]}$. 在中国, 《中国淡水 藻志》第九卷 “蓝藻门藻殖段纲” 描述了 41 个鱼腥藻分类单位,包括 11 个变种 ${ }^{[8]}$; 藻类工作者主要参考 书——中国淡水藻类——系统, 分类及生态》中仅描述了 10 种 ${ }^{[9]}$. 虽然杨丽等报道了 8 个形成水华的鱼腥 藻新记录种 ${ }^{[10]}$, 但是还是有许多常见形成水华的鱼腥藻种类在我国没有报道和描述. 本文对最近在福州塘 坂水库、山仔水库以及宁波东钱湖的水样中鉴定出的 2 种在中国尚未报道的鱼腥藻新纪录种的形态特征进 行描述.

* 中国科学院知识创新工程重要方向项目 (KSCXZ-YW-Z-0932) 和江西省自然科学基金项目 (2010GZN0117) 联合资 助. $2011-11-29$ 收稿;2012-02-07 收修改稿. 李守淳,女,1965 年生, 副教授;E-mail : lsc.982@ 126. com.

** 通信作者;E-mail:reli@ ihb. ac. cn. 


\section{1 材料与方法}

\section{1 样品采集}

在福州塘坂水库、山仔水库以及宁波东钱湖的水体表面中用 $25^{\#}$ 篮绢制作的浮游生物网采集水体中的 浮游藻类.

\section{2 形态观察和测量}

藻丝形态的观察使用 Olympus BX51 型光学显微镜, 外接数码相机 ( QIMAGING Micropublish 5.0 RTV) 与台式机相连. 数码拍照和数据测量通过其附带的图像分析软件 Imagepro express 5.1 进行.

\section{2 结果}

\section{1 威格鱼腥藻 Anabaena viguieri Denis et Frémy 1923 (图 1a, c)}

(Anabaena viguieri Denis et Frémy, 1923; Geitler, 1932; Nygaard, 1949; Watanabe, 1992; Li et al, $2000)^{[5,11-14]}$

藻丝单生, 自由漂浮, 呈线性并附有薄的胶质. 营养细胞具气囊, 球形或近球形, 直径 $4.6 \sim 8.6 \mu \mathrm{m}$. 异形 胞球形, 比营养细胞略宽, 直径 $6.3 \sim 8.6 \mu \mathrm{m}$. 厚壁孢子 (Akinete) 为椭圆形, 直径为 $8.3 \sim 11.3 \mu \mathrm{m}$, 长 $11.0 \sim$ $14.6 \mu \mathrm{m}$, 远离异形胞. 厚壁狍子的长与直径的比率为 $1.14 \sim 1.46$, 平均比率 1.26 .

从细胞大小来看, 异形胞直径以及厚壁狍子的长和直径都比 $\mathrm{Li}$ 等 ${ }^{[11]}$ 所描述的略小, 但形状相似. 该种具 有很薄的胶质, 而其它浮游型的直线型鱼腥藻大多数有着很厚的胶鞘, 这个特点是区别于大多数的主要特点. 而与同样没有胶鞘的近亲鱼腥藻 (A. affinis Lemmermann) 相比, 近亲鱼腥藻常形成束状, 末端细胞较细.

分布: 浙江宁波东钱湖, 日本 Shikatafutago 湖.

\section{2 史密斯鱼腥藻 Anabaena smithii (Komárek) Watanabe 1992 (图 1b)}

(Komárek, 1958; Komárková-Legnerová \& Eloranta, 1992; Watanabe, 1992; Li et al, 2000 $)^{[5,11,15-16]}$

藻丝单生, 自由漂浮, 呈线性且有胶鞘. 营养细胞球型或近球形, 直径 $7.83 \sim 11.48 \mu \mathrm{m}$. 异形胞球形或近 球形, 直径 $11.66 \sim 12.64 \mu \mathrm{m}$. 厚壁狍子球形或近球形, 直径 $17.94 \sim 18.65 \mu \mathrm{m}$, 且与异形胞不邻接, 多数单 生,偶见成对.

从细胞大小来看, 异形胞、厚壁狍子以及营养细胞都在 $\mathrm{Li}$ 等 ${ }^{[11]}$ 所描述的大小范围之内. 该种与 Anabaena solitaria Klebahn 和浮游鱼腥藻 (Anabaena planctonica Brunnthaler) 主要根据狍子形态来区分. Anabaena solitaria 孢子呈圆柱形; 而浮游鱼腥藻狍子为椭圆形 ${ }^{[10-11]}$. 上述表述的新记录种 A. viguieri 的营养细胞和异形 胞都偏小,并且在藻丝体外面的胶鞘以及厚壁孢子的形状都与史密斯鱼腥藻可以较好地区分出来.

分布:福州塘坂水库、山仔水库, 日本 Hirosaki 湖和 Akan 湖.

\section{3 讨论}

鱼腥藻属是由 Bory 在 1822 年以类颤鱼腥藻 (Anabaena oscillariodes Bory) 为模式种创建的一种含有异形 胞的丝状蓝藻,它分布广泛,种类众多,约占蓝藻种类的 $5 \%$. 由于异形胞的固氮现象和机制已被广泛研 究 ${ }^{[17-18]}$, 因此, 鱼腥藻也成为固氮蓝藻中的重要类型, 在全球氮循环中起着重要的作用. 根据生境不同以及 营养细胞产生气囊的特点, 鱼腥藻可分为浮游以及固着两种类型 ${ }^{[19]}$, 再根据 Stup ${ }^{[20]}$ 所提出的鱼腥藻分类标 准即营养细胞的形状大小、异形胞以及孢子的大小、异形胞与孢子的位置关系、末端细胞大小、藻丝颜色和 形状来将鱼腥藻细分为如今的多种分类单位. 本文也是通过这种经典的形态学特征来对藻种进行观察, 并 确定 2 种为中国新记录种.

鱼腥藻的分类系统中, 固着性和浮游性的鱼腥藻是否归为同一个属, Watanabe 等 ${ }^{[21]}$ 提出了质疑. 随着 分子生物学的飞速发展, 根据 DNA 序列的分子分类已经在蓝藻分类系统中广泛应用, 从而也导致鱼腥藻的 分类系统和观点不断修订和改变. 鱼腥藻在种间水平上, 如浮游性的鱼腥藻与束丝藻在分子系统树中就常 常聚在一起, 而且对于混杂着鱼腥藻和束丝藻的多种聚类群中, 还会出现同一种浮游性的鱼腥藻 ${ }^{[22-24]}$. Wacklin 等 ${ }^{[25]}$ 已经将所有的浮游性鱼腥藻归为Dolichospermum (Ralfs ex Bornet et Flahault)这一新属,这样实 
现了浮游性鱼腥藻和固着类的区分, 但是是否所有的浮游性鱼腥藻都归为 Dolichospermum, 同浮游性鱼腥藻 系统关系密切的束丝藻如何归类等问题,并没有得到很好的解决. 所以 Dolichospermum 是否被广泛接受还需 要进一步的研究和论证. 因此, 在本研究中我们还是保留这两个新记录种在鱼腥藻属下. 最近 Akihiro 等 ${ }^{[26]}$ 通过分子系统分析表明营养细胞的大小、孢子的大小以及异形胞和孢子的位置关系是鱼腥藻种间区分的重 要特征,表明目前研究和观察鱼腥藻的典型形态特征作为对其最基本的资料记录和积累还是非常必要的研 究手段. 通过不断对非微囊藻水华蓝藻新类群的形态描述和记录,对我国蓝藻水华的基础生物学和水华发 展态势的掌握都将能提供必要的科学支撑.

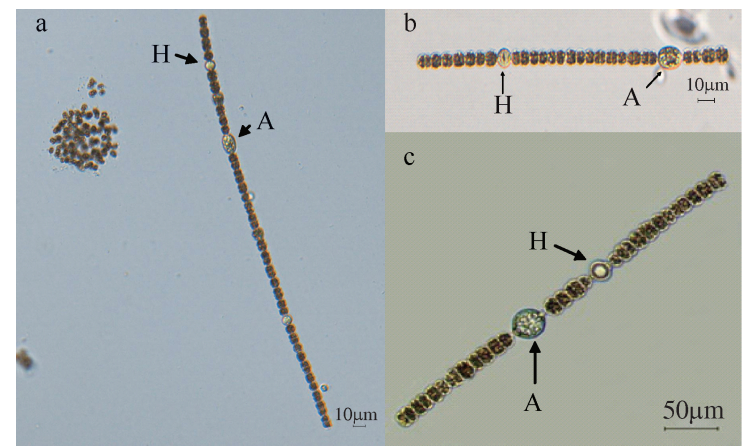

图 1 两个新记录种: $\mathrm{a}$ 野外样品中同微囊藻混合的威格鱼腥藻; b 威格鱼腥藻的单根藻丝; c 史密斯鱼腥藻 (字母 A 表示孢子, 字母 $\mathrm{H}$ 表示异形胞)

Fig. 1 Two newly recorded species of Anabaena: a. Anabaena viguieri in the field sample, mixing with Microcystis; b. A single filament of Anabaena viguieri; c. Anabaena smithii

( Letter “A” and “H” represent akinete and heterocyst, respectively)

\section{4 参考文献}

[ 1 ] Carmichael WW. Health effects of toxin producing Cyanobacteria: “The CyanoHABs”. Human Ecol Risk Assess, 2001 ,7 (5) : 1393-1407.

[ 2 ] 李效宇,宋立荣,刘永定. 微囊藻毒素的产生、检测和毒理学研究. 水生生物学报, 1999,23(5):517-523.

[ 3 ] 刘永梅,刘永定,李敦海等. 滇池束丝藻水华毒性生物检测. 水生生物学报,2004,28(2):216-218.

[ 4 ] 吴忠兴,虞功亮,施军琼等. 我国淡水水华蓝藻——束丝藻属新纪录种. 水生生物学报,2009,33(6):1140-1144.

[ 5 ] Geitler L. Cyanophyceae. In: Rabenhorst's Kryptogamen Floravon Deutschland, Osterreich und der Schweiz 14. Koenigstein Germany Pres. 1932:1196.

[ 6 ] Kondrateva NV. Cyanophyto. In: Vizn. Vodoros. Ukr RSR Press. Vid. “Naukova dumka”, Kiev. 1986,1/2 :524.

[ 7 ] Stamach K. Cyanophyta-sinice, Glaucophyta-Glaucofity. PWN Warszawa: Flora Slodkowodna Polski, Pol. Acad Science Press, $1966,2: 808$.

[8] 朱浩然. 中国淡水藻志 ·第九卷 ·蓝藻门・藻殖段纲. 北京:科学出版社,2007:153-165.

[ 9 ] 胡鸿钧,魏印心. 中国淡水藻类——系统、分类及生态. 北京:科学出版社,2006:173-176.

[10］杨 丽,虞功亮, 李仁辉. 中国鱼腥藻属的八个新记录种. 水生生物学报,2009,33(5):917-922.

[11] Li R, Watanabe M, Watanabe MM. Taxonomic studies of planktic species of Anabaena based on morphological characteristic in cultured strains. Hydrobiologia, $2000,438: 117-138$.

[12] Denis M, Frémy P. Une nouvelle Cyanophycées hétérocystée: Anabaena viguieri. Bulletin de la Société Linnéenne de Normandie, série, 1923, 67:122-125.

[13] Watanabe M. Studies on planktonic blue-green algae 4. Some Anabaena species with straight trichomes in Japan. Bull Natn Sci Mus, Tokyo : Ser. B, 1992, 18:123-137.

[14] Nygaard G. Hydrological studies on some Danish ponds and lakes. Kongl. Danske Vidensk. Selskab., Biol. Skr. 1949, $7: 1-293$. 
[15] Komarkova-Legnerova J. Planktonic blue-green algae(Cyanophyta) from central Finland(Jyvaskyla region) with reference to the genus Anabaena. Arch. Hydrobiologia/Algological Studies, 1992, 67:103-133.

[16] Komarek J. Die taxonomische Revision der planktischen Blaualgen der Tschechoslowakei. In: Komarek J, Ettl H eds. Algologischen Studien. Tschech. Akad. Wiss. Prag., Czechoslovakia, 1958:206.

[17] Adams DG. Multicellulaxity in Cyanobacteria. In Mohan S, Dow C, Cole J eds. Prokaryotic structure and function. A new perspective. Cambridge: Cambridge University Press, $1992: 341-384$.

[18] Wolk CP. Heterrocysts. In: Carr NG, Whitton eds. The biology of Cyanobacteria. Oxford: Blackwell Scientific Publications, $1982: 359-386$.

[19] Komárek J, Anagnostidis K. Modern approach to the classification system of Cyanophytes 4- Nostocales. Archiv für Hydrobiologie Supplement, $1989, \mathbf{8 2}: 247-345$.

[20] Stup BK. Morphological variability of Anabaena strain (Cyanophyceae) under different culture condition. Arch Hydrobiologia/Algological Studies, $1982, \mathbf{3 1}: 165-176$.

[21] Li RH, Watanabe MM. Physiological properties of planktonic species of Anabaena (Cyanobacteria) and their taxonomic value at species level. Arch Hydrobiologia/Algological Studies, $2001,103: 31-46$.

[22] Gugger M, Lyra C, Henriksen P et al. Phylogenetic comparison of the cyanobacterial genera Anabaena and Aphanizomenon. International Journal of Systematic and Evolutionary Microbiology, 2002 ,52 :1867-1880.

[23] Komárek J. Current problems and prospects for the integration of traditional and molecular approaches. Algae, 2006,21 : 349-375.

[24] Rajaniemi P, Hrouzek P, Kastovska K et al. Phylogenetic and morphological evaluation of genera Anabaena, Aphanizomenon, Trichormus and Nostoc (Nostocales, Cyanobacteria). International Journal of Systematic and Evolutionary Microbiolo$g y, 2005,55: 11-26$.

[25] Wacklin P, Hoffmann L, Komárek J. Nomenclatural validation of the genetically revised cyanobacterial genus Dolichospermum (Ralfs ex Bornet et Flahault) comb. nova. Fottea, 2009,9:59-64.

[26] Tuji A, Niiyama Y. Phylogenetic study by the morphological and molecular analyses of Japanese planktonic Anabaena species. Bulletin of the National Science Museum: Series B, 2010,36(2):71-80. 